\title{
Nevşehir İli Güneş Enerji Potansiyelinin Analizi ve Kurulu Güneș Enerji Santralleri
}

\author{
Ayşe Kocalmış Bilhan ${ }^{1 *}$, Serenay Emikönel ${ }^{2}$ \\ 1Nevşehir H.B.V. Üniversitesi, Mühendislik Mimarlık Fakültesi, Elektrik-Elektronik Mühendisliği Bölümü, Nevşehir, Türkiye (ORCID: 0000-0002-5008-6784), \\ akbilhan@nevsehir.edu.tr \\ ${ }^{2}$ Nevşehir H.B.V. Üniversitesi, Elektrik Elektronik Mühendisliği Ana Bilim Dalı Yüksek Lisans Öğrencisi, Nevşehir, Türkiye (ORCID: 0000-0002-2949-8397), \\ serenayemikonel@gmail.com
}

(2nd International Conference on Access to Recent Advances in Engineering and Digitalization (ARACONF)-10-12 March 2021)

(DOI: 10.31590/ejosat.900024)

ATIF/REFERENCE: Bilhan, A.K., Emikönel, S., (2021). Nevşehir İli Güneş Enerji Potansiyelinin Analizi ve Kurulu Güneş Enerji Santralleri. Avrupa Bilim ve Teknoloji Dergisi, (24), 289-294.

\section{$\ddot{O} \mathbf{z}$}

Son yıllarda, enerjiye olan ihtiyaç her geçen gün biraz daha artarken enerji üretim kapasitesi ülkelerin gelişmişlik düzeylerinin bir göstergesi haline gelmiştir. Günümüzde nüfusun hızlı artışı, endüstri 4.0 gibi teknolojik gelişmeler, fosil yakıt kaynaklarının sınırlı olması alternatif enerji kaynaklarının kullanımını oldukça popüler hale getirmiştir. Özellikle 2020 yılında tüm dünyayı etkisi altına alan pandemi ile yaşam alanlarında teknolojik aletlerin daha fazla kullanılmasına ve enerjiye olan ihtiyacın daha da belirgin hale gelmesine sebep olmuştur. Yapılan araştırmalar ile fosil yakıtların yakın gelecekte tükeneceği öngörürken, fosil yakıtların kullanımı ile çevreye verilen zararda açıkça ortaya koyulmaktadır. Bu nedenle araştırmacılar çevreye zarar vermeyen sınırsız enerji kaynağ 1 arayışına başlamıştır. Güneşten, rüzgardan yada jeotermal kaynaklardan elde edilen enerji fosil yakıtlara göre hem çevreye verilebilecek zararı en aza indirmekte hemde tükenmeyen temiz enerji kaynağı olmasıyla çok önemli bir yere sahiptir. Bu alternatif enerji kaynakları içerisinde güneş enerjisi hem güneşin olduğu saatlerde sınırsız olması hem de atık bir ürün oluşturmaması sebebiyle oldukça yaygın bir kullanım alanına sahiptir. Ülkemizin coğrafi konum açısından sahip olduğu güneş enerji potansiyeli oldukça yüksektir ve bu potansiyelin değerlendirilmesi de oldukça önemlidir. Bu çalı̧̧mada İç Anadolu bölgesinde yer alan Nevşehir ili için güneş enerji potansiyeli araştırılmıştır. Nevşehir ilinin merkez ve ilçelerin sahip olduğu güneşlenme süreleri ve işınım şiddetleri hakkında bilgi verilmiştir.

\section{Analysis of the Solar Energy Potential in Nevşehir Province and Installed Solar Power Plants}

\begin{abstract}
In recent years, while the need for energy has increased day by day, energy production capacity has become an indicator of the development levels of countries. Today, alternative energy sources have become more popular because of the rapid increase of the population, technological developments such as industry 4.0 and the limited fossil fuel resources. Especially in 2020 , due to the pandemic that affected the whole world, it caused the use of technological tools more in residential areas and the need for energy became more evident. Recent studies predicted that fossil fuels will be consumed away in the near future and they also reveal the environmental damage. For this reason, researchers have searched for unlimited energy sources that do not harm the environment. Energy obtained from the sun, wind or geothermal resources has a very important place in minimizing the damage to the environment and being an inexhaustible clean energy source compared to fossil fuels. Among these alternative energy sources, solar energy has a
\end{abstract}

*Sorumlu Yazar: akbilhan@nevsehir.edu.tr 
very common usage area because it is unlimited during the hours of the sun, does not produce waste. The solar energy potential in Turkey is quite high of its geographical location. In this study, solar energy potential for Nevşehir province which is located in the Central Anatolia region was investigated. Information has been given about sun light duration and radiation intensity of Nevşehir city center and districts.

Keywords: Energy, Solar Energy, Solar Energy Potential.

\section{Giriş}

Günümüzde enerji, toplumun yaşamsal kalitesini belirleyen en önemli unsurların başında gelmektedir. Enerji ihtiyacı, artan nüfus miktarı, teknolojik gelişmeler ve ekonomik artış ile doğru orantılı olarak günden güne artış göstermektedir. Günlük hayatta her alandan kullanılması, enerji tüketiminin yanı sıra enerji üretiminin de önemini arttırmıştır. Dünya genelinde olduğu gibi Türkiye'de gelişmekte olan bir ülke olarak günden güne daha fazla enerjiye ihtiyaç duymaktadır ve günden güne daha çok enerji üretimi yapmaktadır $[1,2,3]$.

Enerjiye olan ihtiyacın büyük bir çoğunluğu fosil yakıtlarından elde edilmektedir. Fosil yakıtlarının kullanımı beraberinde birçok olumsuz sonucu da getirmektedir. Fosil yakıtlarının yakılmasıyla havaya salınan $\mathrm{CO}_{2}$ gazının meydana getirdiği küresel 1sınma, iklim değişimi gibi olaylar çevreye verilecek zararların artmasına neden olmaktadır. Ayrıca kömür, petrol, linyit ve doğalgaz gibi fosil yakıtlar uzun vadede enerji üretimi mümkün olmayan tükenebilir kaynaklardır. Ülkemizde de fosil yakıtları kaynağının sınırlı olması ve çevreye verilen zararı en aza indirebilmek adına yenilenebilir enerji kaynaklarına yönelim olmuştur $[2,4,5]$.

Yenilenebilir enerji kaynağı, "doğal bir çevrim sürecinde aynen kalabilen ve bir sonraki günde mevcut olabilen enerji kaynağı" olarak ifade edilmektedir [6]. Yenilenebilir enerji kaynakları güneş enerjisi, rüzgar enerjisi, hidrojen enerjisi, hidro enerjisi, gel-git enerjisi ve dalga enerjisi olarak sınıflandırılmaktadır [7]. Yenilenemez enerji kaynaklarına alternatif olarak sunulan yenilenebilir enerji kaynakları ülkelerin dışa bağımlılıklarını azaltması, çevreye verilebilecek zararın en aza indirilmesi ve canlı dosttu olması açısından çok önemli bir yere sahiptir. Yenilenebilir enerji kaynaklarının sınırsız enerji imkanı sağlaması nedeniyle de yenilenebilir enerji kaynaklarına olan ilgi günden güne artmaktadır [5,6].

Enerji üretimi için yenilenebilir enerji kaynaklarında güneş enerjisi önemli bir yere sahiptir. Güneş'in çekirdeğinde hidrojen gazının helyuma gazına dönüşmesi sonucu füzyon reaksiyonu meydana gelir. Oluşan füzyon reaksiyonu sonucunda açığa çıkan 1şınım enerjisi ise güneş enerjisidir [8, 9]. Bir başka deyişle güneş enerjisi, güneşten dünyanın $1 \mathrm{~m}^{2}$ yüzeyine watt olarak düşen enerji olarakta ifade edilebilir. Dünya atmosferinin dışında güneş enerjisinin şiddeti, hemen hemen $1370 \mathrm{~W} / \mathrm{m}^{2}$ ' dir. Bunun yanı sıra yeryüzüne ulaşan miktarı atmosferden kaynaklı olarak 0-1100 W/m ${ }^{2}$ değerleri arasında değişiklik göstermektedir. Bu enerjinin dünyaya gelen küçük bir kısmı bile, insanlığın ihtiyaç duyduğu enerji tüketiminden oldukça çok daha fazladır $[8,10,11]$.

Ülkemizin coğrafi konumu açısından güneş enerji potansiyeli oldukça yüksektir. Güneş enerjisi önemli ölçüde $\mathrm{CO}_{2}$ emisyonlarını en aza indirilmesini sağladığından dolayı ve kullanıldığında herhangi bir zararlı gaz açığa çıkartmadığından dolayı temiz bir enerji kaynağıdır. Güneş enerjisi herhangi bir yakıt gereksiniminde bulunmaması, kullanım esnasında atık madde üretmemesi, gürültü oluşturmaması ve tükenmeyen bir enerji kaynağı olmasıyla bu enerji türüne olan ilgiyi arttırmıştır $[12,13,14]$. Uluslararası Enerji Ajansı (IEA), güneş enerjisinin 2050 yılına kadar ana akım enerji kaynaklarından biri olacağını ve o zaman dünya elektrik üretiminin yaklaşı $\%$ 11'ine katkıda bulunacağını tahmin ediyor $[15,16]$

$\mathrm{Bu}$ çalışmada Nevşehir ili için güneş enerji potansiyeli araştırılarak burada kurulacak Güneş Enerji Santralleri'nden daha verimli faydalanılabilmesi için merkez ve ilçelerinin sahip olduğu güneşlenme süreleri ve 1şınım şiddetleri Enerji ve Tabii Kaynaklar Bakanlığı'ndan alınan veriler incelenerek karşılaştırılmıştır. Literatüre bakıldığında güneş enerji potansiyeli hakkında birçok makale bulunmaktadır. Kaynar çalışmasında Amasya ilinin sahip olduğu güneş enerji potansiyelini araştırmıştır ve Karadeniz Bölgesinde bulunan diğer illerle karşılaştırmıştır [17]. Geçen çalışmasında Hayat ilinde kurulacak güneş enerji santrallerinin en uygun alanlarının belirlenmesini amaçlamıştır. Uygun alanlar CBS ortamında ÇÖKA yöntemiyle analiz edilmiş ve en uygun alanın Erzin ilçesi olduğu tespit edilmiştir [18]. Taşkın ve arkadaşı çalışmalarında Kahramanmaraş'ın güneş enerji potansiyeli araştırılmıştır ve en yüksek güneşlenme süresinin Pazarcık en yüksek 1şınım şiddetinin ise Nurhak olduğu gözlenmiştir. Araştırmalar doğrultusunda güneş enerji potansiyelinin sıcak su elde edilmesi haricinde yeteri kadar kullanılmadığı tespit edilmiştir[19].

\section{Materyal ve Metot}

\subsection{Türkiye'nin Güneş Enerji Potansiyeli}

Türkiye, $783.562 \mathrm{~km}^{2}$ yüzey ölçümüyle, $36^{\circ}-42^{\circ}$ kuzey paralelleri arasında yer almaktadır. Türkiye, coğrafi konumu itibariyle diğer ülkelere kıyasla oldukça yüksek güneş enerjisi potansiyeline sahip ülkedir. Şekil 1'de Enerji ve Tabii Bakanlığ 1 tarafindan hazırlanan Türkiye'nin Güneş Radyasyon Haritası gösterilmiştir [8]. 


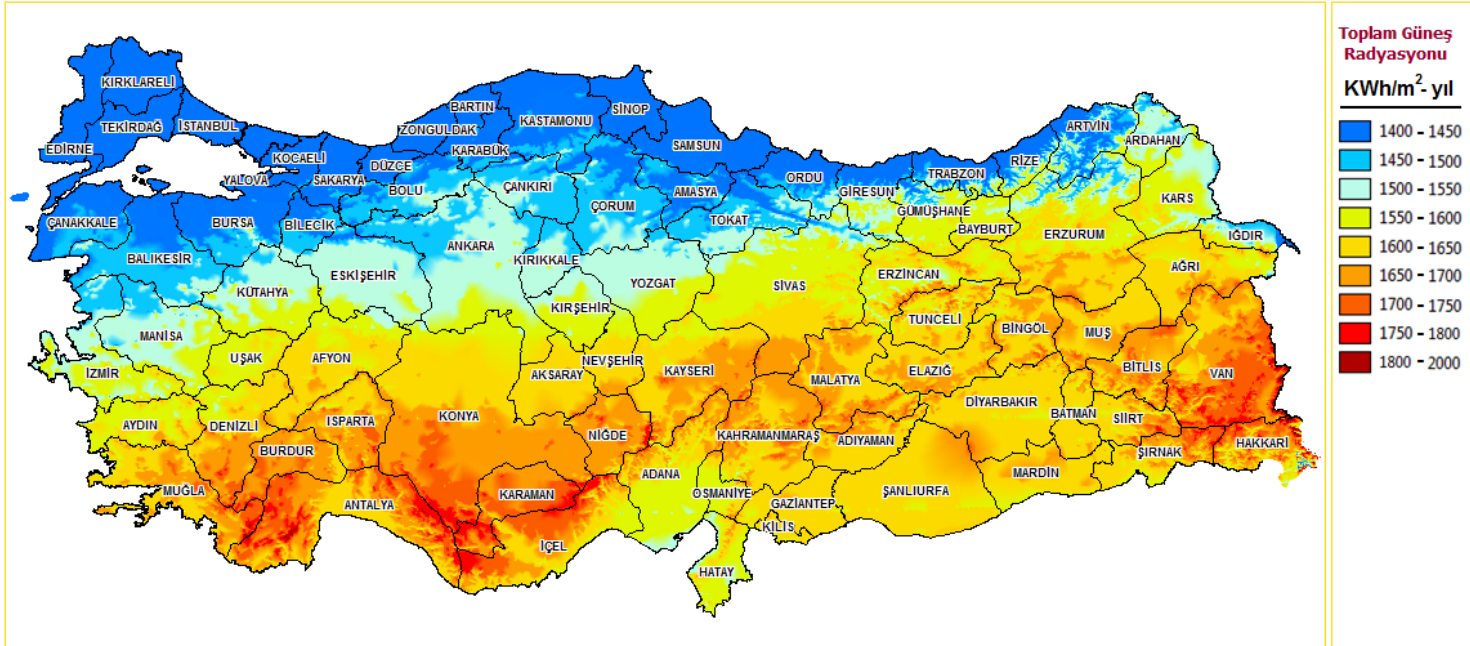

Şekil 1. Türkiyi Güneş Enerji Potansiyeli Atlası (GEPA)

Şekil 1'de gösterilen Türkiye Güneş Enerjisi Potansiyeli Atlası'nda güneş 1şımasından maksimum şekilde faydalanabilecek şehirler açık ve koyu kırmızı renklerle belirtilmiştir. Güneydoğu Anadolu Bölgesi Türkiye'nin en çok güneş enerji potansiyeline sahip bölgelerin başında gelmekte olup, İç Anadolu Bölgesi Tablo 1'de görüldüğü üzere dördüncü sirada yer almaktadir [20].

Tablo1. Bölgelerin Işınım Şiddetleri ve Güneşlenme Süreleri

\begin{tabular}{ccc}
\hline Türkiye'nin Bölgeleri & $\begin{array}{c}\text { Işınım Şiddeti } \\
(\text { KWh/m²-yl) }\end{array}$ & $\begin{array}{c}\text { Güneşlenme } \\
\text { Süreleri (saat/yıl) }\end{array}$ \\
\hline $\begin{array}{c}\text { Güneydoğu Anadolu } \\
\text { Bölgesi }\end{array}$ & 1460 & 2993 \\
\hline $\begin{array}{c}\text { Akdeniz Bölgesi } \\
\text { Doğu Anadolu } \\
\text { Bölgesi }\end{array}$ & 1390 & 2956 \\
\hline $\begin{array}{c}\text { I̧ Anadolu Bölgesi } \\
\text { Ege Bölgesi }\end{array}$ & 1314 & 2664 \\
\hline Marmara Bölgesi & 1168 & 2628 \\
\hline Karadeniz Bölgesi & 1120 & 2738 \\
\hline
\end{tabular}

Şekil 2'de gösterilen değerler ülkemizin aylık bazda ortalama günlük global radyasyon değerlerini göstermektedir [8]. Global radyasyon değerinin en fazla olduğu ay Haziran ayıdır. Türkiye'nin aylık bazda ortalama günlük 1şınım şiddetinin $4,18 \mathrm{kWh} / \mathrm{m}^{2}$-gün, y1lık ortalama toplam global radyasyon değerinin ise $1524,18 \mathrm{kWh} / \mathrm{m}^{2}$-y1l $(4,18 \times 365)$ olduğu görülmektedir.

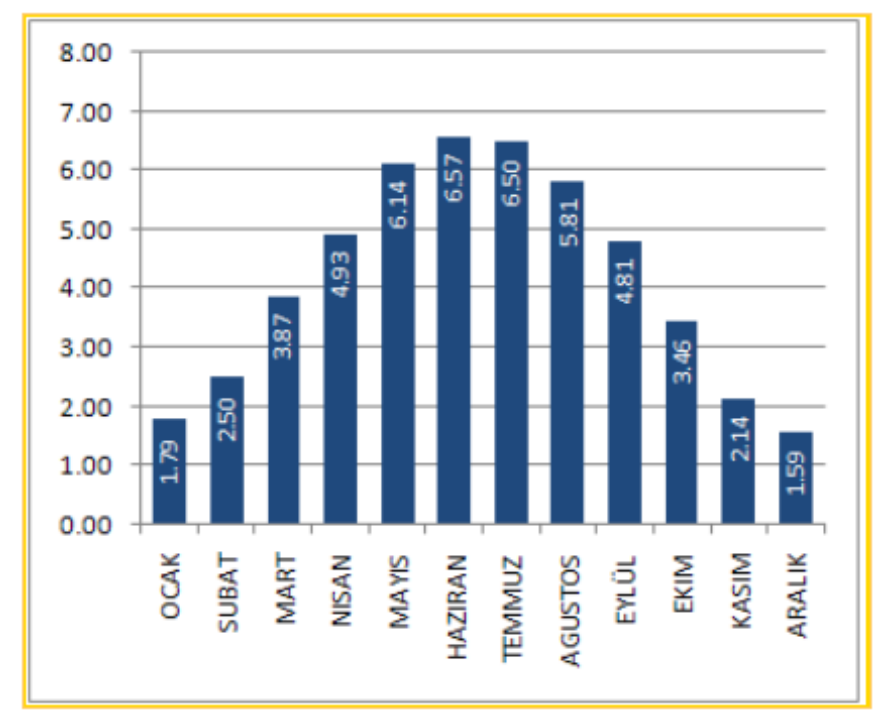

Şekil 2. Türkiye global radyasyon değerleri $\left(\mathrm{KWh} / \mathrm{m}^{2}\right.$-gün)

Şekil 3'te grafikte ülkemizin aylık bazda ortalama güneşlenme süreleri gösterilmiştir [8]. Temmuz ayında güneşlenme süresi maksimum iken Aralık ayında minimumdur. Türkiye'nin aylık bazda ortalama günlük güneşlenme süresi 7,49 saat-gün, yılık ortalama toplam güneşlenme süresi ise 2736,89 saat-yıl $(7,49 \times 365)$ dır. Bu veriler doğrultusunda Türkiye'nin güneşlenme süresi açısından yüksek potansiyele sahip olduğu görülmektedir.

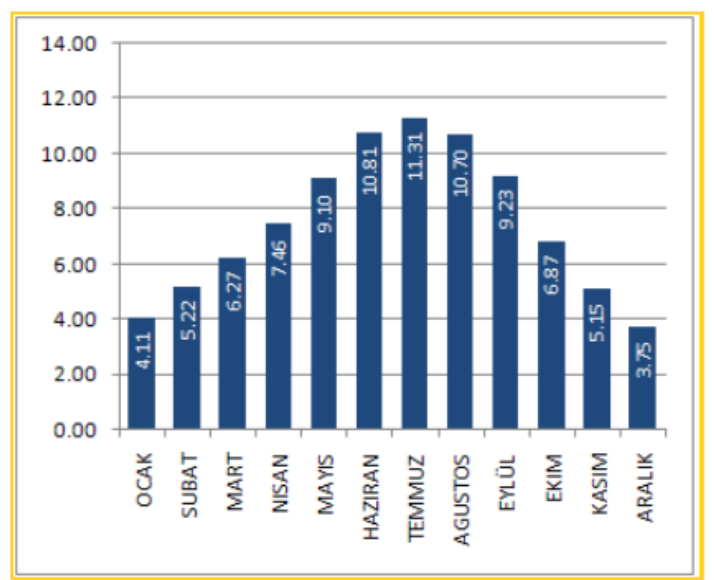

Şekil 3. Türkiye güneşlenme süreleri (saat) 
Şekil 4'te 2014-2020 yılları arasında güneş enerjisinden yararlanmanın yıllara göre diğişimi göterilmiştir [8]. Özellikle 2017 yıllından sonra hızlı bir artış olduğu gözlemlenmektedir. Eylül 2020 sonu itibariylede güneş enerjisine dayalı elektrik kurulu gücümüz $6361 \mathrm{MW}$ '1 bulmuştur.

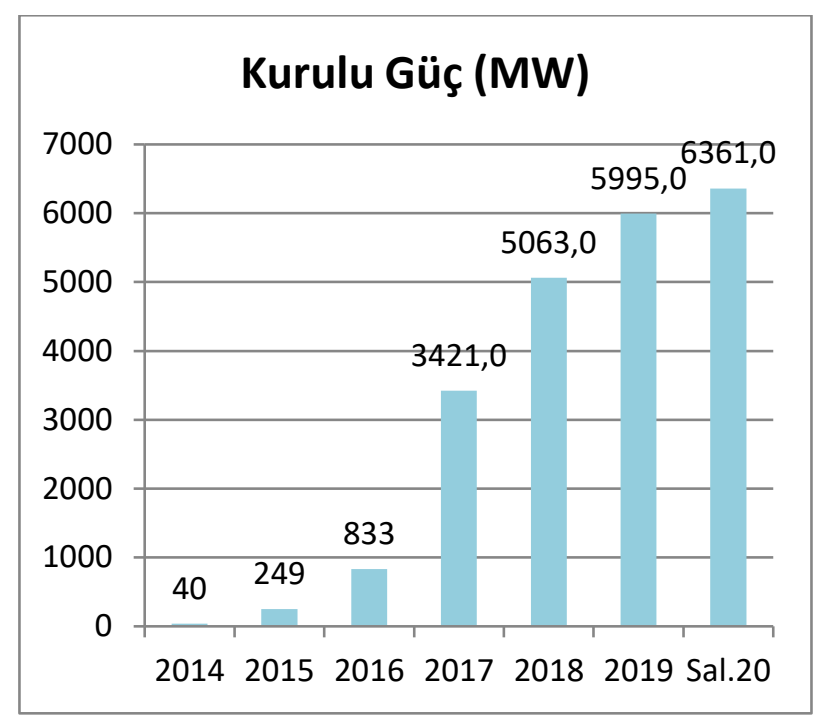

Şekil 4. Türkiye'de Güneş Enerjisinin Gelişimi

\section{Araştırma Sonuçları ve Tartışma}

\subsection{Nevşehir İlinin Güneş Enerji Potansiyeli}

Nevşehir, İç Anadolu Bölgesinde $38^{\circ} 12^{\prime}$ ve $39^{\circ} 20^{\prime}$ kuzey enlemleri ile $34^{\circ} 11^{\prime}$ ve $35^{\circ} 06^{\prime}$ doğu boylamları arasında yer almaktadır. Nevşehir ili, doğudan Kayseri, kuzey doğudan Yozgat, kuzey ve kuzey batıdan Kırşehir, güneyden Niğde ve güney batı ve batıdan Aksaray ileriyle çevrili olup $5467 \mathrm{~km}^{2}$ yüz ölçümüne sahip bir ilimizdir.

Nevşehir ilinin güneş 1 şınım haritası Şekil 5'de gösterilmiştir [8]. Haritadan da görüldüğü üzere Nevşehir ili toplam güneş radyasyon değeri $1500-1750 \mathrm{KWh} / \mathrm{m}^{2}$-yıl güneş 1şınım potansiyeline sahiptir.

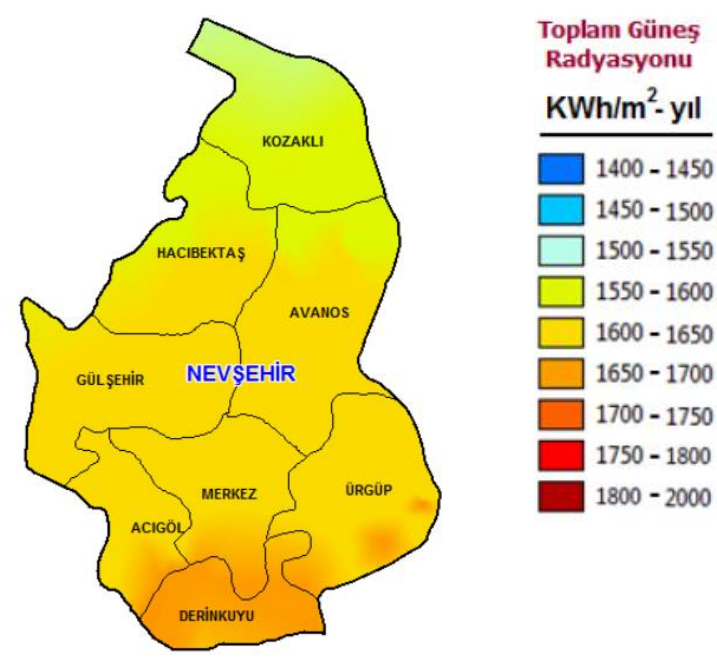

Şekil 5. Nevşehir ili güneş ışınım haritası
Şekil 6'de Nevşehir ilinin aylık ortalama radyasyon değerleri gösterilmiştir [8]. Değerler incelendiğinde en düşük Aralık ayında $1.68 \mathrm{KWh} / \mathrm{m}^{2}$-gün ve en yüksek Temmuz ayında $6.71 \mathrm{KWh} / \mathrm{m}^{2}$-gün olmak üzere değişim gösterdiği görülmektedir.

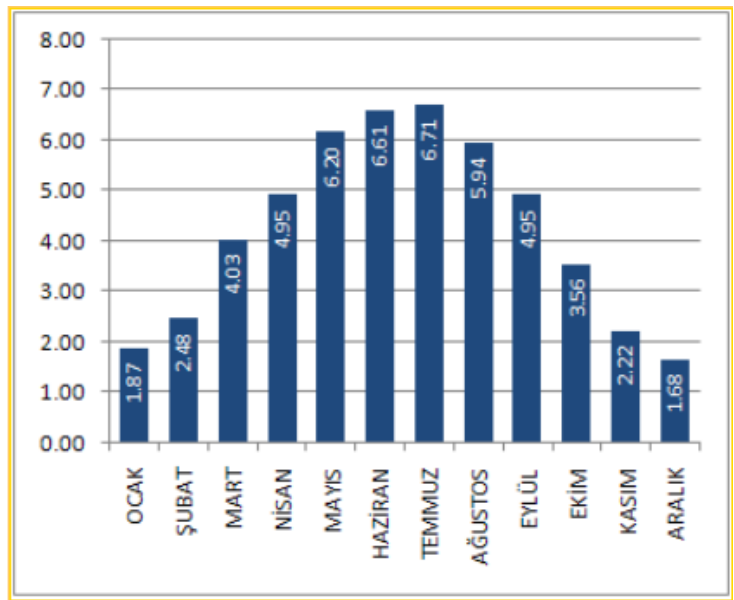

Şekil 6. Nevşehir ili aylık global radyasyon değerleri (KWh/m²-gün)

Şekil 7'de ise Nevşehir İlinin aylık ortalama güneşlenme süreleri gösterilmiştir [8]. Güneşlenme süresinin en düşük değeri Aralık ayında 3.57 saat olup en yüksek değeri ise Temmuz ayında 12.05 saat olmak üzere değişim göstermektedir.

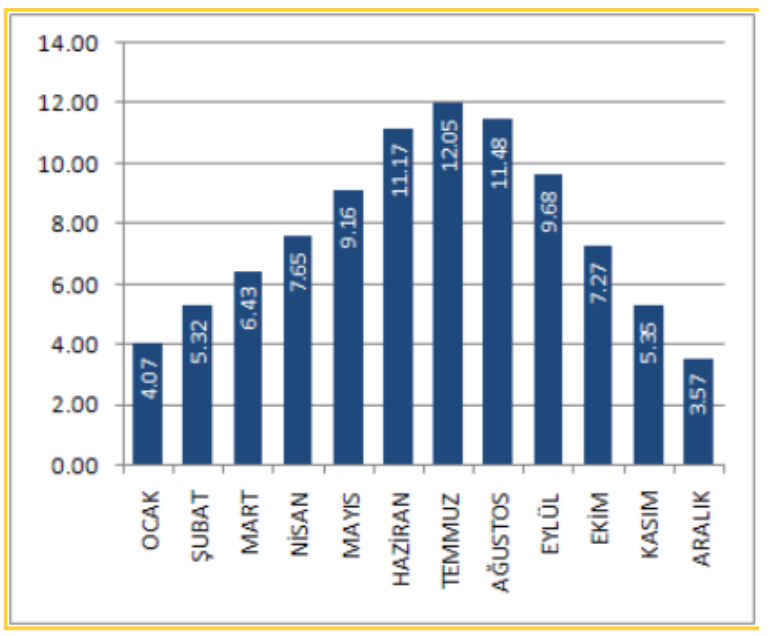

Şekil 7. Nevşehir ili aylık güneşlenme süreleri (saat)

Nevşehir ili yıllık toplam güneşlenme süresi 2844 saat ve yıllık toplam 1şınım miktarı $1568 \mathrm{KWh} / \mathrm{m}^{2}$-yıl (günlük ortalama $4,29 \mathrm{KWh} / \mathrm{m}^{2}$-gün) değerine sahiptir. Bu değerler göz önünde bulundurulduğunda ülke ortalamasının üzerinde bir günüşlenme süresine sahiptir. Bu sebeple Nevşehir ili güneş enerji potansiyeli açısından önemli bir yerdir. Nevşehir ilinde yaz aylarında güneş 1şığından en verimli şekilde faydalanılması sebebiyle güneş enerjisinden elektrik üretimi yaz aylarında en fazladır.

Nevşehir; Kozaklı, Hacıbektaş, Avanos, Gülşehir, Merkez, Ürgüp, Acıgöl ve Derinkuyu olmak üzere toplam 8 ilçeye sahiptir. Tablo2'de bu ilçelere ait y1llık ortalama güneşlenme süreleri verilmiştir [8]. Bu veriler incelendiğinde ilçeler arasında y1llık ortalama güneşlenme süresi en yüksek 7,90 h ile Derinkuyu iken en düşük 7,61 h ile Kozaklı'dır. Tablo 3'de ise global radyasyon değerleri verilmiştir [8]. $\mathrm{Bu}$ değerler doğrultusunda $4,37 \mathrm{KWh} / \mathrm{m}^{2}$ ile Derinkuyu ilk sirada yer alırken, 4,15 ile Kozaklı son sırada yer almaktadır. 
Tablo 2. Nevşehir ilinin merkez ve ilçelerinin yıllık ortalama güneşlenme süreleri (saat)

\begin{tabular}{|c|c|c|c|c|c|c|c|c|c|c|c|c|c|}
\hline $\begin{array}{l}\text { Güneşlenme } \\
\text { Süresi (saat) }\end{array}$ & ฮัँ & 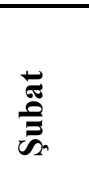 & 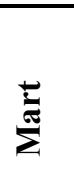 & 吾 & 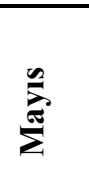 & 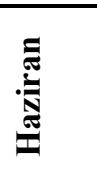 & 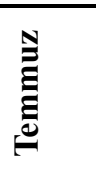 & 总 & 章 & 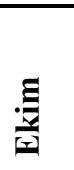 & 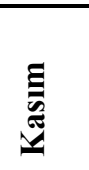 & $\frac{\underline{y}}{\bar{E}}$ & $\begin{array}{l}\text { Yıllık } \\
\text { Ortalama } \\
\text { Güneş } \\
\text { Enerji }\end{array}$ \\
\hline Kozaklı & 3,99 & 5,26 & 6,33 & 7,59 & 8,99 & 10,95 & 11,84 & 11,28 & 9,42 & 7,08 & 5,21 & 3,46 & 7,61 \\
\hline Hacıbektaş & 4,03 & 5,30 & 6,47 & 7,67 & 9,08 & 11,08 & 11,97 & 11,39 & 9,57 & 7,18 & 5,28 & 3,51 & 7,71 \\
\hline Avanos & 4,04 & 5,30 & 6,34 & 7,60 & 9,11 & 11,13 & 12,01 & 11,45 & 9,63 & 7,25 & 5,31 & 3,52 & 7,72 \\
\hline Gülş̧ehir & 4,09 & 5,33 & 6,56 & 7,74 & 9,15 & 11,17 & 12,05 & 11,48 & 9,68 & 7,25 & 5,37 & 3,59 & 7,78 \\
\hline Merkez & 4,10 & 5,37 & 6,48 & 7,69 & 9,25 & 11,29 & 12,17 & 11,58 & 9,79 & 7,36 & 5,43 & 3,63 & 7,84 \\
\hline Ürgüp & 4,12 & 5,33 & 6,37 & 7,61 & 9,22 & 11,28 & 12,14 & 11,56 & 9,79 & 7,39 & 5,41 & 3,61 & 7,81 \\
\hline Acıgöl & 4,10 & 5,37 & 6,56 & 7,73 & 9,29 & 11,30 & 12,19 & 11,58 & 9,82 & 7,35 & 5,45 & 3,69 & 7,86 \\
\hline Derinkuyu & 4,16 & 5,40 & 6,52 & 7,69 & 9,37 & 11,35 & 12,23 & 11,60 & 9,93 & 7,44 & 5,49 & 3,73 & 7,9 \\
\hline
\end{tabular}

Tablo 3. Nevşehir ilinin merkez ve ilçelerinin global radyasyon değerleri

\begin{tabular}{|c|c|c|c|c|c|c|c|c|c|c|c|c|c|}
\hline $\begin{array}{l}\text { Işınım } \\
\text { Şiddeti } \\
\left(\mathbf{K W h} / \mathbf{m}^{2} \text { - }\right. \\
\text { gün) }\end{array}$ & రूँ & $\begin{array}{l}\overline{\tilde{N}} \\
\bar{E} \\
\bar{B}\end{array}$ & 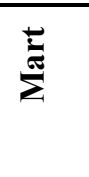 & 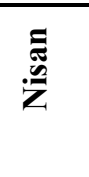 & $\sum_{\sum}^{\infty}$ & 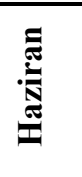 & 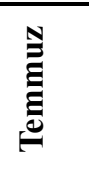 & 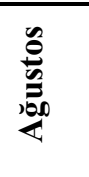 & 齐 & 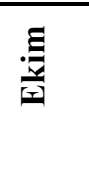 & 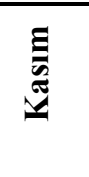 & 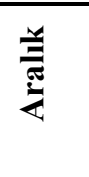 & $\begin{array}{l}\text { Yıllık } \\
\text { Ortalama } \\
\text { Güneş } \\
\text { Enerji }\end{array}$ \\
\hline$\overline{\text { Kozaklı }}$ & 1,80 & 2,38 & 3,91 & 4,85 & 6,13 & 6,49 & 6,43 & 5,84 & 4,84 & 3,45 & 2,10 & 1,60 & 4,15 \\
\hline Hacıbektaş & 1,84 & 2,48 & 3,99 & 4,92 & 6,19 & 6,58 & 6,66 & 5,93 & 4,93 & 3,50 & 2,18 & 1,65 & 4,23 \\
\hline Avanos & 1,86 & 2,49 & 4,02 & 4,94 & 6,18 & 6,59 & 6,69 & 5,93 & 4,93 & 3,53 & 2,20 & 1,67 & 4,25 \\
\hline Gülşehir & 1,87 & 2,45 & 4,02 & 4,93 & 6,14 & 6,57 & 6,69 & 5,95 & 4,93 & 3,60 & 2,21 & 1,70 & 4,25 \\
\hline Merkez & 1,90 & 2,50 & 4,08 & 4,99 & 6,25 & 6,66 & 6,83 & 5,97 & 4,99 & 3,60 & 2,27 & 1,70 & 4,31 \\
\hline Ürgüp & 1,91 & 2,51 & 4,09 & 5,01 & 6,26 & 6,68 & 6,82 & 5,97 & 4,99 & 3,60 & 2,28 & 1,70 & 4,31 \\
\hline Acıgöl & 1,90 & 2,53 & 4,10 & 5,00 & 6,25 & 6,68 & 6,82 & 5,99 & 5,00 & 3,64 & 2,29 & 1,70 & 4,32 \\
\hline Derinkuyu & 1,93 & 2,64 & 4,15 & 5,04 & 6,33 & 6,73 & 6,90 & 6,03 & 5,06 & 3,69 & 2,30 & 1,73 & 4,37 \\
\hline
\end{tabular}

Nevşehir ilinde, aktif beş ve yapım aşamasında dört olmak üzere 9 güneş enerji santrali bulunmaktadır. Tablo 4'de bu santraller ve kurulu güçleri hakkında bilgi verilmiştir [21].

Tablo 4. Nevşehir ilinin güneş enerji santralleri

\begin{tabular}{|l|l|l|l|}
\hline Santral Ad1 & Durumu & Firma & $\begin{array}{l}\text { Kurulu } \\
\text { Güç (MW) }\end{array}$ \\
\hline $\begin{array}{l}\text { Derinkuyu } \\
\text { Güneş Enerji } \\
\text { Santrali }\end{array}$ & Aktif & & $17 \mathrm{MW}$ \\
\hline $\begin{array}{l}\text { Ede Yol Yap1 } \\
\text { Enerji ve } \\
\text { Güldan GES }\end{array}$ & Aktif & $\begin{array}{l}\text { Ede Yol } \\
\text { Yapı Enerji }\end{array}$ & $4,00 \mathrm{MW}$ \\
\hline $\begin{array}{l}\text { Beşiktaş ve } \\
\text { Kadıköy } \\
\text { Güneş Enerji } \\
\text { Santrali }\end{array}$ & Aktif & & $1,97 \mathrm{MW}$ \\
\hline $\begin{array}{l}\text { Blok Bims } \\
\text { Güneş }\end{array}$ & Aktif & Blok Bims & $0,28 \mathrm{MW}$ \\
\hline
\end{tabular}

\begin{tabular}{|c|c|c|c|}
\hline Santrali & & & \\
\hline $\begin{array}{l}\text { Nevşehir } \\
\text { Belediyesi } \\
\text { Güneş Enerji } \\
\text { Santrali }\end{array}$ & Aktif & $\begin{array}{l}\text { Nevşehir } \\
\text { Belediyesi }\end{array}$ & $0,18 \mathrm{MW}$ \\
\hline $\begin{array}{l}\text { Hamzali } \\
\text { Güneş Enerji } \\
\text { Santrali }\end{array}$ & $\begin{array}{l}\text { Yapım } \\
\text { Aşamasında }\end{array}$ & & 5,90 MW \\
\hline $\begin{array}{l}\text { Tekno Enerji } \\
\text { Nevşehir } \\
\text { GES }\end{array}$ & $\begin{array}{l}\text { Yapım } \\
\text { Aşamasında }\end{array}$ & $\begin{array}{l}\text { Tekno } \\
\text { Enerji }\end{array}$ & $3,00 \mathrm{MW}$ \\
\hline $\begin{array}{l}\text { Hacibektaş } \\
\text { Belediyesi } \\
\text { Güneș Enerji } \\
\text { Santrali } \\
\end{array}$ & $\begin{array}{l}\text { Yapım } \\
\text { Aşamasında }\end{array}$ & $\begin{array}{l}\text { Hacıbektaş } \\
\text { Belediyesi }\end{array}$ & $1,00 \mathrm{MW}$ \\
\hline $\begin{array}{l}\text { BEC Tarım } \\
\text { Güneş Enerji } \\
\text { Tesisi }\end{array}$ & $\begin{array}{l}\text { Yapım } \\
\text { Aşamasında }\end{array}$ & BEC Tarım & $0,50 \mathrm{MW}$ \\
\hline
\end{tabular}


Nevşehir ili için kurulu ve yapım aşamasında bulunan dört GES'inde faaliyete geçmesiyle GES'ler bugünkünden çok daha fazla miktarda ekonemiye destek sağlayacaktır.

\section{Sonuç}

$\mathrm{Bu}$ çalışma ile Nevşehir ilinin sahip olduğu güneş enerji potansiyelin araştırılmış olup bulgular dahilinde yıllık toplam güneşlenme süresi yaklaşık 2844 saat, y1llık toplam global radyasyon değerinin ise yaklaşık $1568 \mathrm{KWh} / \mathrm{m}^{2}$ olduğu tespit edilmiştir. $\mathrm{Bu}$ değerlerde İç Anadolu bölgesinde yer alan Nevşehir ilinin güneş enerjisi bakımından önemini ortaya koymaktadir.

Nevşehir ilinde kurulacak güneş enerji sistemlerinden daha iyi bir şekilde verim alabilmek için il ve merkezlerin güneşlenme süreleri ve global radyasyon değerleri karşılaştırılmıştır. Elde edilen sonuçlar doğrultunda ilçelerin 1şınım şiddetlerinin sıralamas1; Derinkuyu, Acıgöl, Ürgüp, Merkez, Avanos, Gülşehir, Hacıbektaş, Kozaklı şeklindedir. Güneşlenme sürelerine göre ise; Derinkuyu, Acıgöl, Merkez, Ürgüp, Gülşehir, Avanos, Hacıbektaş, Kozaklı şeklinde olduğu tespit edilmiştir. $\mathrm{Bu}$ sonuçlar doğrultusunda Nevşehir'in güneş enerji potansiyeli yüksek olan Derinkuyu, Acıgöl ve Merkez güneş enerji santrallerinin kurulaması için en uygun bölgelerdir.

Nevşehir ilinde aktif olarak enerji üretimi yapan toplam 23,43 MWkurulu güce sahip 5 Güneş Enerji Santrali bulunmaktadır. Yapım aşamasında olan 4 GES'inde faaliyete geçmesi ile bu günkünden daha fazla enerji üretimi yapılacaktır. Bunun yanı sıra şuan yapım aşamasında olan güneş enerji santralleri ve kurulacak yeni santraller sayesinde yeni iş imkanları da sunacaktır. Bölgesel açıdan incelendiğinde Güneydoğu Anadolu Bölgesi kadar verimli olmasa da İç Anadolu Bölgesi de güneşlenme süreleri ve 1şınım şiddetleri göz önünde bulundurulduğunda önemi anlaşılmaktadır.

\section{Kaynakça}

[1] İzgeç, M. M. (2020). Türkiye Yenilenebilir Enerji Kapasitesi Devreye Alma İşleminin Darboğaz Analizi. Fırat Üniversitesi Mühendislik Bilimleri Dergisi, 32(2), 499-508.

[2] Özyakışır, Ö. ve Ünver, S. (2020). Yenilenebilir Enerji Kaynaklarına Dayalı Lisanssız Elektrik Üretimi. Ankara Hacı Bayram Veli Üniversitesi Hukuk Fakültesi Dergisi, 4, 195-226.

[3] Kocalmış Bilhan, A. (2019). Design of output buck-boost Converter for Solar Inverter. 4.International Conference on Material Science and Technology (IMSTEC 2019, 228-232.

[4] Eltas, İ. (2020). Tek Eksenli Güneş Takip Sistemi Veriminin Erzurum Koşullarında Belirlenmesi.

[5] Bükün, N. (2017). Siirt Yöresi İçin Tek Eksenli Güneş Takip Sistemli Güneş Panellerinin Enerji Verimliliğinin İncelenmesi.

[6] Yılmaz, E. A. ve Öziç, H. C. (2018). Türkiye'nin Yenilenebilir Enerji Potansiyeli Ve Gelecek Hedefleri. ODÜ Sosyal Bilimler Araştırmalarl Dergisi (ODÜSOBİAD), 8(3), 525-535.

[7] Koç, E. ve Kaya, K. (2015). Enerji Kaynaklar1-Yenilenebilir Enerji Durumu. Mühendis ve Makine, 56(668), 36-47.

[8] YEGM, (2020). Yenilenebilir Enerji Kaynağı Genel Müdürlüğü. $\quad$ http://www.yegm.gov.tr/MyCalculator/D efault.aspx
[9] Oğuz, M. ve Akkurt, Ş. (2017). Kayseri İlinin Yenilenebilir Enerji Potansiyeli. Ömür Halisdemir Üniversitesi Mühendislik Bilimleri Dergisi, 6(2), 362-374.

[10] Çifci, A. ve Altundağ, E. (2017). Burdur Bölgesi Güneş Enerjisi Potansiyelinin Elektrik Üretimimnde Kullanımı. Mesleki Bilimler Dergisi, 6(2), 111-120.

[11] Çırak, B. (2019) Karaman İlinde Yenilenebilir Enerji Uygulamaları. KMÜ Mühendislik ve Doğa Bilimleri Dergisi, 1(1), 19-49.

[12] Badak, U. ve Y1ldız, A. B. (2020). Fotovoltaik Güneş Paneli Sistemlerinde Maksimum Güç Noktası İzleyicisinin Verime Etkisi. Journal of the Institute of Science and Technology, 10(4), 2496-2507.

[13] Bulut, N., Kuncan, M. ve Horoz, S. (2018). Türkiye'de Güneş Enerjisinin Kullanım Alanları ve Siirt Güneş Enerji Potansiyeli. Ahtamara I. Uluslararast Multidisipliner Çalışmalar Kongresi, 1315-1319.

[14] Alcan, Y., Demir, M. ve Duman, S. (2018). Sinop İlinin Güneş Enerjisinden Elektrik Üretim Potansiyelinin Ülkemiz Ve Almanya İle Karşılaştırarak İncelenmesi. El-Cezeri Fen ve Mühendislik Dergisi, 5(1), 35-44.

[15] Dinçer, F. (2011). The analysis on photovoltaic electricity generation status, potential and policies of the leading countries in solar energy, Renew. Sustain. Energy Rev. 15 (1) 713-720.

[16] Moosavian, S., Rahim, N., Selvaraj, J., Solangi, K. (2013). Energy policy to promote photovoltaic generation, Renew. Sustain. Energy Rev. 25, 44-58.

[17] Kaynar, N. K. (2020). Yenilenebilir Enerji Kaynaklarından Güneş Enerjisinin Amasya İlindeki Potansiyeli. Bilge International Journal of Science and Technology Research, 4(2), 48-54.

[18] Geçen, R. (2019). Hatay İlinde Güneş Enerjisi Potansiyeli ve Güneş Enerjisi Potansiyeli ve Güneş Enerjisi Santrali Kurulacak Alanların Belirlenmesi. Turkish Studies - Social Sciences, 14(6), 3031-3054.

[19] Taşkın, O. ve Korucu, T. (2014). Kahramanmaraş İli İçin Güneş Enerjisi Potansiyeli ve Kullanım Olanakları. KSÜ Doğa Bilim Dergisi, 17(4), 12-16.

[20] Power Enerji, https://www.powerenerji.com/turkiye-gunesenerjisi-potansiyel-haritasi-bolge-il-guneslenme$\underline{\text { sureleri.html }}$

[21] Enerji Atlas1, Nevşehir Elektrik Santrali. https://www.enerjiatlasi.com/sehir/nevsehir/ 